Journal of Mathematics and Statistics 3 (4): 268-276, 2007

ISSN 1549-3644

(C) 2007 Science Publications

\title{
Some Algorithms to Identify Rational Structures in Stochastic Processes with Expectations
}

\author{
Concepción González-Concepción, María Candelaria Gil-Fariña \\ and Celina Pestano-Gabino \\ Department of Applied Economics, Faculty of Economics Science \\ and Business Administration, University of La Laguna, Campus of Guajara, \\ s/n, 38701 La Laguna, Tenerife, The Canary Islands, Spain.
}

\begin{abstract}
This research was concerned with the identification of rational models in stochastic processes and we use the Padé-Laurent Approximation to identify a Transfer-Function Model with Expectations. We mention the T-table method and focus in studying the generalised epsilon-algorithm, emphasizing the main role of the statistical significance of their numerical entries. Empirical work is made for non-causal TF models using both simulated and economic real data.
\end{abstract}

Key words: Padé approximation, epsilon-algorithm, transfer-function model, expectations

\section{INTRODUCTION}

Over the last two decades, several studies have considered the use of rational approximation and related techniques in stochastic processes. Some of these techniques (e.g. ${ }^{[5,2,14,20,8]}$, which are closely related to the Padé Approximation and Orthogonal Polynomials (e.g. ${ }^{[1,6]}$ ), constitute useful tools for modelling time series and computing the orders of their rational structures.

Some interesting research provide reliable methods to specify the causal linear Transfer-Function (TF) model, a special case of VARMA models that constitutes one of the most frequent dynamic specification in time series modelling (e.g. ${ }^{[5,14,13,19]}$ ).

The inclusion of expectations for the input variables in this type of models implies considering to non-causal models proposed ${ }^{[10]}$ that we present in Section 2. This approach has provided not only a general framework to study dynamic relationships between variables with expected values but also extending the identification methods that have been proposed for classic causal models. The methodological basis which underlies this approach is the Padé-Laurent Approximation $^{[7]}$. In this context we deal with the Toeplitz and the generalised epsilon methods. Section 3 is concerned with the generalised epsilon algorithm to identify a TF model with expectations. Also, the statistical significance of numerical entries in the algorithm is introduced analogously as in the classical case.

Empirical work is made using SCA package ${ }^{[15]}$, MATHEMATICA Software ${ }^{[20]}$ and FORTRAN Programming. We contribute with numerical findings for non-causal TF models. Empirical results point out the role of the statistical significance for the epsilonalgorithm to get parsimonious formulations and reduce possible competing models to only a few for further testing.

In an economic context, we illustrate this proposal for studying some consequences in the banana production's evolution in the Canary Islands, the main banana producer area in European Union.

The research concludes with the most relevant conclusions and some open questions of interest.

\section{THE NON-CAUSAL TF MODEL}

A TF model with expectations ${ }^{[10]}$ for a bivariate and stationary process $z_{t}^{\prime}=\left(y_{t}, x_{t}^{\prime}\right)$ with $y_{t}$ onedimensional and $x_{t}^{\prime}=\left(x_{t}^{*}, x_{t}^{* *}\right)^{\prime}$ of dimension $m$ can be expressed as follows

$$
\begin{aligned}
& \mathrm{y}_{\mathrm{t}}=\sum_{\mathrm{i}=1}^{\mathrm{m}} \sum_{\mathrm{j}=0}^{\infty} \mathrm{v}_{\mathrm{ij}}^{*} \mathrm{x}_{\mathrm{it}-\mathrm{j}}^{*}+\sum_{\mathrm{i}=1}^{\mathrm{m}} \sum_{\mathrm{j}=0}^{\infty} \mathrm{v}_{\mathrm{ij}}^{* *} \mathrm{x}_{\mathrm{it}+\mathrm{j}}^{* *}+\mathrm{N}_{\mathrm{t}} ; \\
& \mathrm{N}_{\mathrm{t}}=\frac{\theta_{\mathrm{q}}(\mathrm{L})}{\phi_{\mathrm{p}}(\mathrm{L})} \mathrm{a}_{\mathrm{t}} ; \mathrm{a}_{\mathrm{t}} \sim \mathrm{N}\left(0, \sigma^{2}\right)
\end{aligned}
$$

Corresponding Author: Concepción González-Concepción, Department of Applied Economics, Faculty of Economics Science and Business Administration, University of La Laguna, Campus of Guajara, s/n, 38701 La Laguna. Tenerife. The Canary Islands. Spain 
Now $y_{t}$ (output variable) is explained by two terms: a systematic one, which is described by one or more independent variables $\mathrm{x}_{\mathrm{it}}{ }^{*}$ (real data) and that includes $\mathrm{x}_{\mathrm{it}}{ }^{* *}$ (expected values) that can follow or not the same distribution and a non-systematic component which is described by an ARMA process.

The existence of a dynamic, one-way, causal relation $\mathrm{x}_{\mathrm{it}}{ }^{*}, \mathrm{x}_{\mathrm{it}}{ }^{* *} \rightarrow \mathrm{y}_{\mathrm{t}}$ is assumed. Therefore, a unidirectional relationship is given on $\mathrm{y}_{\mathrm{t}}$ by both contemporary and lagged effects of the input variables but also by the expected values described by $\mathrm{x}_{\mathrm{it}}{ }^{* *}$.

In the case of a single input variable and defining $\mathrm{L}^{\mathrm{j}}\left(\mathrm{x}_{\mathrm{it}}\right)=\mathrm{x}_{\mathrm{it-j}} \forall \mathrm{j} \in \mathrm{Z}$, a closed form for the TF model with expectations can be expressed as

$$
y_{t}=\sum_{j=-\infty}^{\infty} v_{j} L^{j} x_{t}+N_{t}
$$

where $x_{t-j}=x_{t-j}^{*}$ if $j \geq 0, x_{t-j}=x_{t-j}^{* *}$ if $j<0$ and $V(L)=\sum_{j=-\infty}^{\infty} v_{j} L^{j}$ denotes the IRF, now the double infinite series of weights in Z.

A finite representation for $\mathrm{v}$ (L) with orders $(p+a, s+b)$ and $(-d, r)$ could be given by the expression

$$
\begin{aligned}
& V(L)=\frac{\sum_{i=p+a}^{s+b} w_{i} L^{i}}{\left(1+\sum_{i=1}^{d} \alpha_{-i} L^{-i}\right)\left(1+\sum_{i=1}^{r} \beta_{i} L^{i}\right)} \\
& =\frac{\sum_{i=p+a}^{s+b} w_{i} L^{i}}{\sum_{j=-d}^{r} \psi_{j} L^{j}}=\frac{W_{p+a, s+b}(L)}{\Psi_{-d, r}(L)}
\end{aligned}
$$

In this finite structure for $\mathrm{V}(\mathrm{L}), \mathrm{W}_{\mathrm{p}+\mathrm{a}, \mathrm{s}+\mathrm{b}}(\mathrm{L})$ and $\Psi_{-\mathrm{d}, \mathrm{r}}$ (L) are Laurent polynomial operators in $\mathrm{L}$.

The lagged and lead effects on $y_{t}$ due to changes in $\mathrm{x}_{\mathrm{t}}$ appear expressed in $\mathrm{W}_{\mathrm{p}+\mathrm{a}, \mathrm{s}+\mathrm{b}}(\mathrm{L})$ with $\mathrm{a}<0$ and $\mathrm{b} \geq 0$ respectively:

$$
\begin{aligned}
& \mathrm{W}_{\mathrm{p}+\mathrm{a}, \mathrm{s}+\mathrm{b}}(\mathrm{L})=\mathrm{w}_{\mathrm{p}+\mathrm{a}} \mathrm{L}^{\mathrm{p}+\mathrm{a}}+\mathrm{w}_{\mathrm{p}+\mathrm{a}+1} \mathrm{~L}^{\mathrm{p}+\mathrm{a}+1}+\ldots+ \\
& \mathrm{w}_{\mathrm{a}} \mathrm{L}^{\mathrm{a}}+\mathrm{w}_{\mathrm{b}} \mathrm{L}^{\mathrm{b}}+\ldots+\mathrm{w}_{\mathrm{s}+\mathrm{b}} \mathrm{L}^{\mathrm{s}+\mathrm{b}} \quad(\mathrm{p}, \mathrm{s} \in \mathrm{Z})
\end{aligned}
$$

Furthermore,

$$
\begin{aligned}
& \Psi_{-\mathrm{d}, \mathrm{r}}(\mathrm{L})=\psi_{-\mathrm{d}} \mathrm{L}^{-\mathrm{d}}+\psi_{-\mathrm{d}+1} \mathrm{~L}^{-\mathrm{d}+1}+\ldots+ \\
& \Psi_{\mathrm{r}-1} \mathrm{~L}^{\mathrm{r}-1}+\psi_{\mathrm{r}} \mathrm{L}^{\mathrm{r}} \quad(\mathrm{d}, \mathrm{r} \in \mathrm{N})
\end{aligned}
$$

It is considered that $\mathrm{W}_{\mathrm{p}+\mathrm{a}, \mathrm{s}+\mathrm{b}}(\mathrm{L})$ and $\Psi_{-\mathrm{d}, \mathrm{r}}(\mathrm{L})$ have no common factors and model stability is guaranteed in terms of the roots for the characteristic polynomial $\Psi_{-\mathrm{d}, \mathrm{r}}(\mathrm{L})$.

In accordance with the guidelines proposed by the Padé-Laurent Approximation for studying doubly infinite series, a TF model with expectations can be identified by using the Toeplitz method ${ }^{[10]}$ which generalises the corner method ${ }^{[2,14,20]}$ given for causal models.

Therefore, a similar method to that one described for the causal model can now be used. For instance, given the sequence of weights $v \equiv\left(v_{j}\right)_{j \in Z}$ and of relative ones $\eta \equiv\left(\eta_{j}\right)_{j \in Z}$, that is, $\eta_{j}=v_{j} / v_{j, \text { max }}$, the Toeplitz determinants

$$
T_{f, g}(\eta)=\operatorname{det}\left[\left(\eta_{f+k-j}\right)_{k, j=1}^{g}\right]
$$

provide the next theoretic "corner characterization" for $\mathrm{v}(\mathrm{L})$ in a non causal TF model: $\mathrm{V}(\mathrm{L})$ has a rational representation with orders (p,s,d,r,a,b), $\mathrm{V}(\mathrm{L})=\frac{\mathrm{W}_{\mathrm{p}+\mathrm{a}, \mathrm{s}+\mathrm{b}}(\mathrm{L})}{\Psi_{-\mathrm{d}, \mathrm{r}}(\mathrm{L})}$, if and only if

$$
\begin{aligned}
& \mathrm{T}_{\mathrm{f}, \mathrm{r}}(\eta) \neq 0, \mathrm{f} \geq \mathrm{b}+\mathrm{s} ; \mathrm{T}_{\mathrm{b}+\mathrm{s}, \mathrm{g}}(\eta) \neq 0, \mathrm{~g} \geq \mathrm{r} \\
& \mathrm{T}_{\mathrm{f}, \mathrm{d}}(\eta) \neq 0, \mathrm{f} \leq \mathrm{p}+\mathrm{a} ; \mathrm{T}_{\mathrm{p}+\mathrm{a}, \mathrm{g}}(\eta) \neq 0, \mathrm{~g} \geq \mathrm{d} \\
& \mathrm{T}_{\mathrm{f}, \mathrm{g}}(\eta)=0, \quad(\mathrm{f} \geq \mathrm{b}+\mathrm{s}+1, \mathrm{~g} \geq \mathrm{r}) \wedge \\
& \quad(\mathrm{f} \leq \mathrm{p}+\mathrm{a}-1, \mathrm{~g} \geq \mathrm{d}+1) \wedge(\mathrm{a}<\mathrm{f}<\mathrm{b})
\end{aligned}
$$

This theoretic characterization can be clearly displayed in a tabular form (T-table) in Table 1.

This proposal extends the well-known classic approach to carry out the identification of a causal TF model starting from the sequence $\left(\hat{\eta}_{\mathrm{i}}\right)=\left(\hat{\eta}_{\mathrm{ij}}\right)_{j \in \mathrm{N}}$, where $x_{t}^{\prime}=x_{t}^{*}$, that is, $x_{t}^{* *}$ is not considered. In this particular case, another possible numerical method to provide a rational characterization is the epsilonalgorithm ${ }^{[12]}$. The study of the statistical significance in the epsilon-algorithm can be seen $\mathrm{in}^{[3]}$ and $^{[12]}$. Other methods have recently been proposed by ${ }^{[11]}$.

Some adequate transformations in the sequence of relative weights could be necessary to avoid computational instability in some specific cases.

Next, we refer to the generalised epsilon-algorithm in a non-causal context and contribute with by studying the statistical significance of their numerical entries. 
Table 1: T-table

\begin{tabular}{|c|c|c|c|c|c|c|c|c|c|}
\hline \multirow[b]{2}{*}{$f$} & \multicolumn{5}{|l|}{$\mathrm{g}$} & \multirow[b]{2}{*}{$\mathrm{r}$} & \multirow[b]{2}{*}{$\mathrm{r}+1$} & \multirow[b]{2}{*}{$\ldots$} & \multirow[b]{2}{*}{$\mathrm{M}$} \\
\hline & 1 & $\ldots$ & $\mathrm{d}$ & $\mathrm{d}+1$ & $\ldots$ & & & & \\
\hline $\mathrm{M}^{\prime \prime}$ & $\ldots$ & $\ldots$ & $\ldots$ & & & $\ldots$ & $\ldots$ & $\ldots$ & $\ldots$ \\
\hline$\ldots$ & $\ldots$ & $\ldots$ & $\mathrm{x}$ & 0 & 0 & 0 & 0 & 0 & $\ldots$ \\
\hline $\mathrm{p}+\mathrm{a}-1$ & $\mathrm{~T}_{\mathrm{p}+\mathrm{a}-1,0}$ & $\mathrm{x}$ & $\mathrm{T}_{\mathrm{p}+\mathrm{a}-1, \mathrm{~d}-1}$ & 0 & 0 & 0 & 0 & 0 & $\ldots$ \\
\hline $\mathrm{p}+\mathrm{a}$ & $\mathrm{T}_{\mathrm{p}+\mathrm{a}, 0}$ & $\mathrm{x}$ & $\mathrm{T}_{\mathrm{p}+\mathrm{a}, \mathrm{d}-1}$ & $\mathrm{~T}_{\mathrm{p}+\mathrm{a}, \mathrm{d}}$ & $\mathrm{x}$ & $\mathrm{x}$ & $\mathrm{x}$ & $\mathrm{x}$ & $\ldots$ \\
\hline$\ldots$ & $\ldots$ & $\ldots$ & $\ldots$ & $\ldots$ & $\ldots$ & $\ldots$ & $\ldots$ & $\ldots$ & $\ldots$ \\
\hline $\mathrm{a}$ & $\mathrm{T}_{\mathrm{a}, 0}$ & $\mathrm{x}$ & $\mathrm{x}$ & $\mathrm{x}$ & $\mathrm{x}$ & $\mathrm{x}$ & $\mathrm{x}$ & $\mathrm{x}$ & $\ldots$ \\
\hline$a+1$ & 0 & 0 & 0 & 0 & 0 & 0 & 0 & 0 & $\ldots$ \\
\hline \multicolumn{10}{|l|}{$\ldots$} \\
\hline$b+1$ & 0 & 0 & 0 & 0 & 0 & 0 & 0 & 0 & $\ldots$ \\
\hline $\mathrm{b}$ & $\mathrm{T}_{\mathrm{b}, 0}$ & $\mathrm{x}$ & $\mathrm{x}$ & $\mathrm{x}$ & $\mathrm{x}$ & $\mathrm{x}$ & $\mathrm{x}$ & $\mathrm{x}$ & $\ldots$ \\
\hline$\ldots$ & $\ldots$ & & $\ldots$ & & $\ldots$ & & $\ldots$ & & $\ldots$ \\
\hline $\mathrm{s}+\mathrm{b}$ & & $\ldots$ & & & & $\mathrm{T}_{\mathrm{s}+\mathrm{b}, \mathrm{r}-1}$ & $\mathrm{~T}_{\mathrm{s}+\mathrm{b}, \mathrm{r}}$ & $\mathrm{x}$ & $\ldots$ \\
\hline $\mathrm{s}+\mathrm{b}+1$ & $\ldots$ & & $\ldots$ & & $\ldots$ & $\mathrm{T}_{\mathrm{s}+\mathrm{b}+1, \mathrm{r}-1}$ & 0 & 0 & 0 \\
\hline$\ldots$ & & $\ldots$ & & & & $\mathrm{x}$ & 0 & 0 & 0 \\
\hline $\mathrm{M}^{\prime}$ & $\ldots$ & 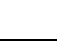 & $\ldots$ & & $\ldots$ & $\ldots$ & $\ldots$ & $\ldots$ & $\ldots$ \\
\hline
\end{tabular}

\section{THE GENERALIZED EPSILON-ALGORITHM AND ITS STATISTICAL SIGNIFICANCE}

The epsilon algorithm constitutes an alternative method to identify a causal TF model. This iterative procedure can be derived from the cross rule between five adjacent Padé Approximants $\left(\mathrm{see}^{[6]}\right)$. If $\varepsilon_{2 \mathrm{k}}^{\mathrm{n}}=[(\mathrm{n}+\mathrm{k}) / \mathrm{k}]_{\mathrm{f}}(\mathrm{z})$ is the Padé Approximants of orders $n+k$ (numerator) and $\mathrm{k}$ (denominator) for a given formal power series $f(z)=\sum_{i=0}^{\infty} c_{i} z^{i}$, given a fixed value of $z$ and we define $\varepsilon_{2 \mathrm{k}+1}^{\mathrm{n}}$ in an adequate form, the numbers $\varepsilon_{2 \mathrm{k}}^{\mathrm{n}}$ can be related for all $\mathrm{k}, \mathrm{n}$ as follows

$$
\forall \mathrm{k}, \mathrm{n} \in \mathrm{Z} \quad \varepsilon_{\mathrm{k}+1}^{\mathrm{n}}=\varepsilon_{\mathrm{k}-1}^{\mathrm{n}+1}+\frac{1}{\varepsilon_{\mathrm{k}}^{\mathrm{n}+1}-\varepsilon_{\mathrm{k}}^{\mathrm{n}}}
$$

Displaying these values in a tabular form we obtain a useful tool to identify if $\mathrm{f}$ is a rational function indeed. Let $\mathrm{f}(\mathrm{z})=\sum_{\mathrm{i}=0}^{\infty} \mathrm{c}_{\mathrm{i}} \mathrm{z}^{\mathrm{i}}$ be a formal power series; defining $\varepsilon_{0}^{\mathrm{n}}(\mathrm{c})=\mathrm{c}_{\mathrm{n}}, \varepsilon_{-1}^{\mathrm{n}}(\mathrm{c})=0, \forall \mathrm{n} \geq 0$, then $\varepsilon_{2 \mathrm{k}}^{\mathrm{n}}(\mathrm{c})=0$ if and only if

$$
\Delta(\mathrm{n}, \mathrm{k}+1)=\operatorname{det}\left[\left(\mathrm{c}_{\mathrm{n}-\mathrm{k}-2+\mathrm{i}+\mathrm{j}}\right)_{\mathrm{i}, \mathrm{j}=1}^{\mathrm{n}+1}\right]
$$

associated to $c=\left(c_{n}\right)$ is zero. Consequently, it can be proved that $f$ is a rational function with degrees $[p / q]$ if and only if

$$
\varepsilon_{2 q}^{\mathrm{p}-\mathrm{q}}(\mathrm{c}) \neq 0 \text { and } \varepsilon_{2 \mathrm{q}}^{\mathrm{j}}(\mathrm{c})=0, \forall \mathrm{j}>\mathrm{p}-\mathrm{q}
$$

For a stochastic process with expectations we can generalize this previous result as follows:

An approximated finite structure with orders $(\mathrm{p}, \mathrm{s}, \mathrm{r}, \mathrm{d}, \mathrm{a}, \mathrm{b})$ for $\mathrm{V}(\mathrm{L})$ is given by (1)-(2)-(3) if and only if

$$
\begin{array}{ll}
\varepsilon_{2 \mathrm{r}}^{\mathrm{s}+\mathrm{b}-\mathrm{r}}(\eta) \neq 0, & \varepsilon_{2 \mathrm{r}}^{\mathrm{j}}(\eta)=0, \quad \forall \mathrm{j}>\mathrm{s}+\mathrm{b}-\mathrm{r} \\
\varepsilon_{2 \mathrm{~d}}^{\mathrm{p}+\mathrm{a}-\mathrm{d}}(\eta) \neq 0, & \varepsilon_{2 \mathrm{~d}}^{\mathrm{j}}(\eta)=0, \quad \forall \mathrm{j}<\mathrm{p}+\mathrm{a}-\mathrm{d}
\end{array}
$$

These conditions are shown in the epsilon-table (Table 2). Another condition,

$$
\eta_{j}=0, \quad j=a+1, \ldots, b-1
$$

leads to identify the lag and lead values, that is, b and a respectively, in the response of the output to input changes.

Given a stochastic process, in order to study the significance of epsilon-values associated to the estimated sequence $\hat{\eta}=\left(\hat{\eta}_{j}\right)_{j=-K . . K}$, for a chosen $K$ value, it is advisable to consider the asymptotic standard deviation. This can be made by computing the t-Student statistical values

$$
\frac{\varepsilon_{2 \mathrm{k}}^{\mathrm{n}}(\hat{\eta})}{\sqrt{\operatorname{var}\left(\varepsilon_{2 \mathrm{k}}^{\mathrm{n}}(\hat{\eta})\right)}}, \mathrm{k} \geq 0, \mathrm{n}=-\mathrm{K} . . \mathrm{K}-\mathrm{k}
$$


Table 2: Epsilon-table

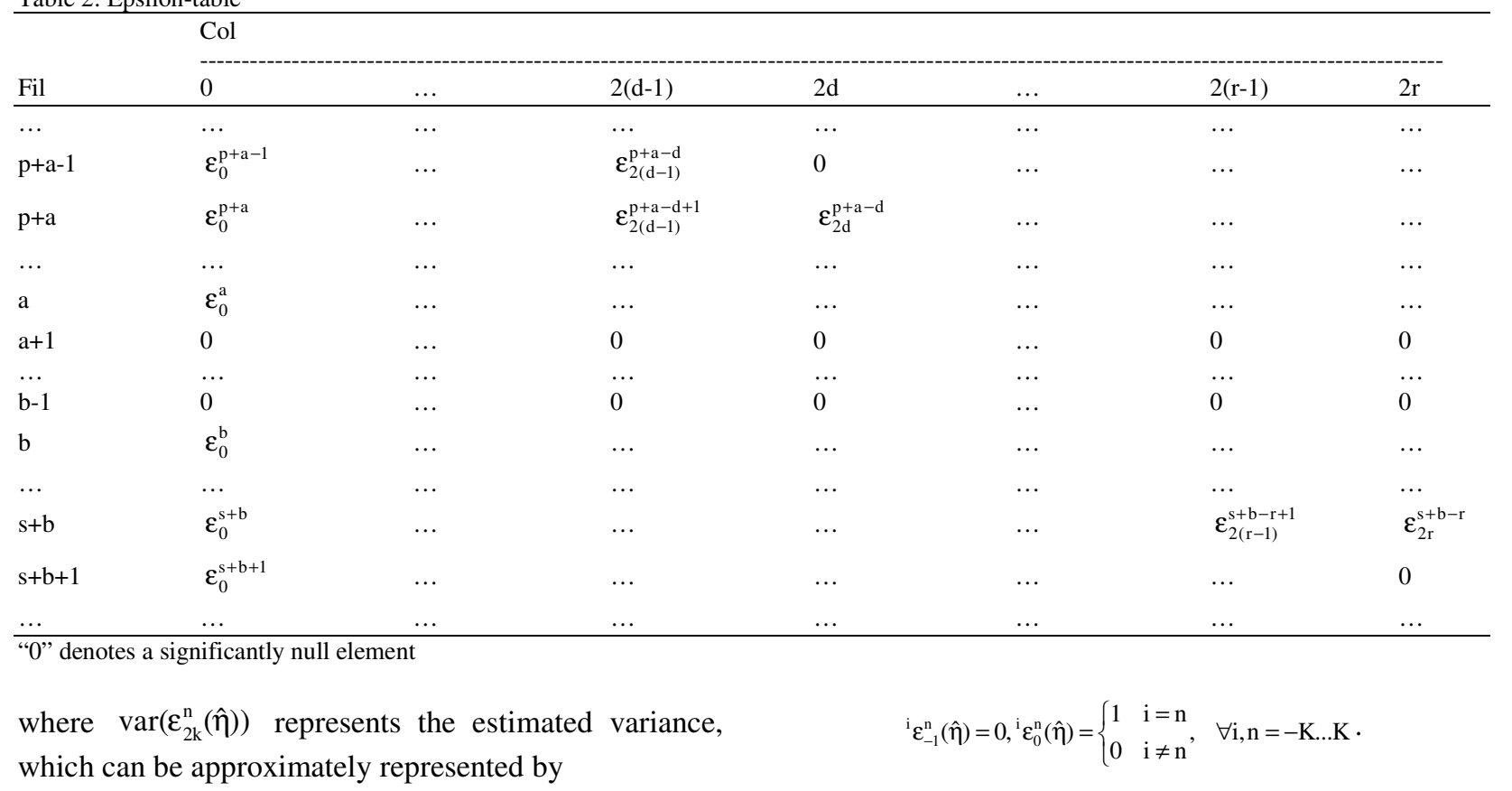

$$
\operatorname{var}\left(\varepsilon_{2 k}^{n}(\hat{\eta})\right) \cong F_{k}^{n^{\prime}}(\hat{\eta}) M_{k}^{n}(\hat{\eta}) F_{k}^{n}(\hat{\eta})
$$

$M_{k}^{n}(\hat{\eta})$ is the sample variance-covariance matrix of the sequence $\left(\hat{\eta}_{\mathrm{n}}, \ldots, \hat{\eta}_{\mathrm{k}+\mathrm{n}}\right)$, that is,

$$
M_{k}^{n}(\hat{\eta})=\left(m_{i j}^{k, n}\right)_{i, j=1, \ldots, k+1}
$$

where

$$
\mathrm{m}_{\mathrm{ii}}^{\mathrm{k}, \mathrm{n}}=\operatorname{var}\left(\hat{\eta}_{\mathrm{k}+\mathrm{i}-1}\right)
$$

and

$$
m_{i j}^{k, n}=\operatorname{cov}\left(\hat{\eta}_{n+i-1}, \hat{\eta}_{n+j-1}\right)
$$

Finally,

$$
F_{k}^{n}(\hat{\eta})=\left({ }^{n} \varepsilon_{k}^{n}(\hat{\eta}), \ldots,{ }^{n+k} \varepsilon_{k}^{n}(\hat{\eta})\right)
$$

with

$$
\begin{aligned}
& { }^{\mathrm{i}} \varepsilon_{\mathrm{k}}^{\mathrm{n}}(\hat{\eta}) \equiv \frac{\partial \varepsilon_{\mathrm{k}}^{\mathrm{n}}}{\partial \eta_{\mathrm{i}}}(\hat{\eta})= \\
& \left\{\begin{array}{cc}
{ }^{\mathrm{i}} \varepsilon_{\mathrm{k}-2}^{\mathrm{n}+1}(\hat{\eta})+\frac{{ }^{\mathrm{i}} \varepsilon_{\mathrm{k}-1}^{\mathrm{n}}(\hat{\eta})-{ }^{\mathrm{i}} \varepsilon_{\mathrm{k}-1}^{\mathrm{n}+1}(\hat{\eta})}{\left[\varepsilon_{\mathrm{k}-1}^{\mathrm{n}+1}(\hat{\eta})-\varepsilon_{\mathrm{k}-1}^{\mathrm{n}}(\hat{\eta})\right]^{2}} & \mathrm{i}=\mathrm{n}, \mathrm{n}+1, \ldots, \mathrm{n}+\mathrm{k} \\
0 & \text { otherwise }
\end{array}\right.
\end{aligned}
$$

Note that the initial values are now

With all these values we can construct a new table, the Asymptotic Standard Deviation Table, for the epsilontable containing the associated value to the t-Student statistical $\frac{\varepsilon_{2 k}^{\mathrm{n}}(\hat{\eta})}{\sqrt{\operatorname{var}\left(\varepsilon_{2 k}^{\mathrm{n}}(\hat{\eta})\right)}}$ in the same position that $\varepsilon_{2 \mathrm{k}}^{\mathrm{n}}(\hat{\eta})$. Consequently, we can consider the value $\varepsilon_{2 \mathrm{k}}^{\mathrm{n}}$ in Table 2 as a significantly null element if the $\frac{\varepsilon_{2 k}^{n}(\hat{\eta})}{\sqrt{\operatorname{var}\left(\varepsilon_{2 k}^{n}(\hat{\eta})\right)}}$ value associated is minor than a given critical value (1.28 or a greater one).

\section{EMPIRICAL RESULTS}

Empirical work is made using MATHEMATICA software to estimate weights $\hat{v}=\left(\hat{v}_{j}\right)_{j=-9 . .9}$ by OLS method. Having computed the sequence of relative weights $\left(\hat{\eta}=\left(\hat{\eta}_{j}\right)_{j=-9 . .9}\right)$ and the variance-covariance matrix, the generalised epsilon algorithm was implemented using FORTRAN programming language. In order to illustrate the generalized epsilon-algorithm and the role of the statistical significance to confirm the identified patterns, numerical results were obtained for the average weights.

Example 4.1 a simulated model: We consider the following simulated single input $\mathrm{TF}$ model with expectations: 
J. Math. \& Stat., 3 (4): 268-276, 2007

Table 3: The epsilon-table for $\hat{\boldsymbol{\eta}}=\left((-\mathbf{1})^{\mathbf{j}} \hat{\boldsymbol{\eta}}_{\mathbf{j}}\right)_{\mathbf{j}=-\mathbf{9} . \ldots 9}$. Average of 200 simulations

\begin{tabular}{|c|c|c|c|c|c|c|c|c|c|c|}
\hline & 0 & 2 & 4 & 6 & 8 & 10 & 12 & 14 & 16 & 18 \\
\hline-9 & -0.039 & & & & & & & & & \\
\hline-8 & -0.050 & -0.040 & & & & & & & & \\
\hline-7 & 0.030 & 2.500 & 0.098 & & & & & & & \\
\hline-6 & 0.108 & 0.161 & -0.552 & 0.048 & & & & & & \\
\hline-5 & 0.139 & 0.112 & 0.102 & 0.137 & 0.163 & & & & & \\
\hline-4 & -0.039 & 0.099 & 0.110 & 0.183 & 0.142 & -0.040 & & & & \\
\hline-3 & 0.577 & 0.185 & 0.134 & 0.120 & 0.106 & 0.068 & 0.033 & & & \\
\hline-2 & -0.500 & 0.000 & 0.048 & 0.041 & 0.175 & 0.202 & -0.063 & 0.013 & & \\
\hline-1 & 0.435 & 0.073 & 0.043 & 0.048 & 0.198 & 0.172 & 0.091 & 0.059 & 0.036 & \\
\hline 0 & -0.154 & 0.011 & 0.083 & 0.006 & -0.443 & 0.024 & 0.014 & 0.156 & 0.028 & 0.042 \\
\hline 1 & 0.075 & -0.112 & -0.421 & -0.072 & -0.087 & 0.015 & 0.025 & -0.066 & 0.006 & \\
\hline 2 & -0.950 & -0.278 & -0.178 & -0.084 & -0.074 & -0.044 & -0.028 & -0.017 & & \\
\hline 3 & 1.000 & 0.128 & 0.032 & 0.018 & 0.025 & 0.046 & 0.117 & & & \\
\hline 4 & -0.577 & -0.020 & 0.014 & 0.022 & 0.013 & -0.001 & & & & \\
\hline 5 & 0.284 & 0.027 & 0.042 & -0.110 & -0.007 & & & & & \\
\hline 6 & -0.081 & 0.038 & 0.017 & 0.004 & & & & & & \\
\hline 7 & 0.096 & 0.064 & 0.003 & & & & & & & \\
\hline 8 & 0.057 & 0.083 & & & & & & & & \\
\hline 9 & 0.134 & & & & & & & & & \\
\hline
\end{tabular}

Table 4: Asymptotic standard deviation to epsilon-table for $\hat{\boldsymbol{\eta}}=\left((-\mathbf{1})^{\mathbf{j}} \hat{\boldsymbol{\eta}}_{\mathbf{j}}\right)_{\mathbf{j}=-\mathbf{9} . .9}$. Average of 200 simulations

\begin{tabular}{|c|c|c|c|c|c|c|c|c|c|c|}
\hline & 0 & 2 & 4 & 6 & 8 & 10 & 12 & 14 & 16 & 18 \\
\hline-9 & -0.297 & & & & & & & & & \\
\hline-8 & -0.339 & -0.427 & & & & & & & & \\
\hline-7 & 0.208 & 0.006 & 0.061 & & & & & & & \\
\hline-6 & 0.738 & 0.249 & -0.011 & 0.110 & & & & & & \\
\hline-5 & 0.958 & 1.160 & 1.687 & 0.843 & 0.867 & & & & & \\
\hline-4 & -0.266 & 1.214 & 1.681 & 0.305 & 1.127 & -0.042 & & & & \\
\hline-3 & 3.955 & 2.781 & 2.774 & 2.994 & 3.354 & 1.406 & 0.309 & & & \\
\hline-2 & -3.417 & 0.006 & 0.994 & 0.779 & 1.182 & 0.809 & -0.116 & 0.133 & & \\
\hline-1 & 2.967 & 1.119 & 0.903 & 0.976 & 0.961 & 1.063 & 1.232 & 1.623 & 1.453 & \\
\hline 0 & -1.052 & 0.145 & 0.997 & 0.131 & -0.436 & 0.362 & 0.184 & 0.515 & 1.136 & 1.003 \\
\hline 1 & 0.511 & -1.251 & -1.338 & -2.093 & -2.287 & 0.252 & 0.308 & -0.849 & 0.305 & \\
\hline 2 & -6.543 & -4.120 & -3.636 & -2.440 & -2.278 & -1.702 & -1.194 & -0.768 & & \\
\hline 3 & 6.877 & 2.038 & 0.666 & 0.405 & 0.519 & 0.651 & 0.499 & & & \\
\hline 4 & -3.960 & -0.298 & 0.270 & 0.553 & 0.169 & -0.004 & & & & \\
\hline 5 & 1.954 & 0.386 & 0.350 & -0.025 & -0.024 & & & & & \\
\hline 6 & -0.559 & 0.554 & 0.056 & 0.009 & & & & & & \\
\hline 7 & 0.660 & 0.708 & 0.005 & & & & & & & \\
\hline 8 & 0.388 & 1.232 & & & & & & & & \\
\hline 9 & 1.001 & & & & & & & & & \\
\hline
\end{tabular}

$$
\begin{aligned}
& \mathrm{y}_{\mathrm{t}}=\frac{0.8 \mathrm{~L}^{-3}+0.2 \mathrm{~L}^{-2}-0.25 \mathrm{~L}^{-1}+1.25 \mathrm{~L}^{2}+0.75 \mathrm{~L}^{3}}{1-0.5 \mathrm{~L}} \mathrm{x}_{\mathrm{t}}+\varepsilon_{\mathrm{t}} \\
& (1-0.5 \mathrm{~L}) \mathrm{x}_{\mathrm{t}}=\mathrm{a}_{\mathrm{t}} ; \quad \mathrm{a}_{\mathrm{t}} \square \mathrm{N}(0,1) ; \quad \varepsilon_{\mathrm{t}} \square \mathrm{N}(0,4)
\end{aligned}
$$

with orders $(-2,1,0,1,-1,2)$.

In order to obtain asymptotic results, 200 dataset were simulated with 130 data each one. First data were not considered in order to avoid numerical instability. Therefore, a 113 effective data series was considered for each dataset. The epsilon and asymptotic standard deviations values for the average over 200 simulations with the statistical significance of their numerical entries are shown in Table 3 and 4 respectively.
According to the identified pattern given in Table 2 , epsilon values in Table 3 clearly exhibit the simulated model structure $(-2,1,0,1,-1,2)$. However, other possible patterns could be also observed without studying previously the statistical significance of numerical entries, for example, $(-2,2,0,0,-1,2)$. Table 4 is obviously needed, considering the Asymptotic Standard Deviation. The shaded regions in this table indicate the first elements minor that 1.28 (corresponding to significantly null elements in Table 3). In this way, $a=-1, b=2, p=-2, s=1, d=0$, $\mathrm{r}=1$ and therefore the orders $(-2,1,0,1,-1,2)$ can be identified in a more clear way. Nevertheless, other possibilities that also appear in the table, such as $(-2,3$, 
$-1,0,-1,2),(-2,3,0,0,-1,2),(-2,1,-1,1,-1,2)$, are less parsimonious.

It can be also concluded that as the number of simulations increases the results are clarify still more.

From the perspective of real data modelling it frequently happens that according to certain critical values, the statistical significance table reduce possible competing patterns to only a few for further estimating and testing.

Example 4.2 multivariate models to banana from canary islands: production, income and cost: A three-dimensional relationship between Production, Income and Average Production Cost is studied, taking data for the period 1938-2002 in the Canary Islands. Banana production and farmer income historical series were taken from ${ }^{[4,18,16]}$. We had to consider data about water and fertiliser collected from the accounting of three representative private properties in the North of Tenerife. Linear interpolation was necessary to obtain a reasonable sample size ${ }^{[17]}$. Data are shown in Fig. 1, 2 and 3 .

Some necessary logarithmic and first-differences transformations have been achieved to obtain a more homogenous variance in data and guarantee both stationary series. Let us define at time $t, z_{t}=(1-$ L) $\operatorname{lnProd}_{t}$, where $\operatorname{Prod}_{t}$ is banana Production in thousands of tons; $x_{t}=(1-L) \operatorname{lnI}_{t}$ where $I_{t}$ is the farmer indexed Income (ptas $/ \mathrm{kg})$ (Index $1996=100)$, including the market price and the compensatory aid; $\mathrm{y}_{\mathrm{t}}$ $=(1-\mathrm{L}) \ln \operatorname{Cost}_{\mathrm{t}}$, where Cost is the indexed Average Cost (ptas $/ \mathrm{kg}) \quad($ Index $1996=100)$. "In" represents the logarithm operator.

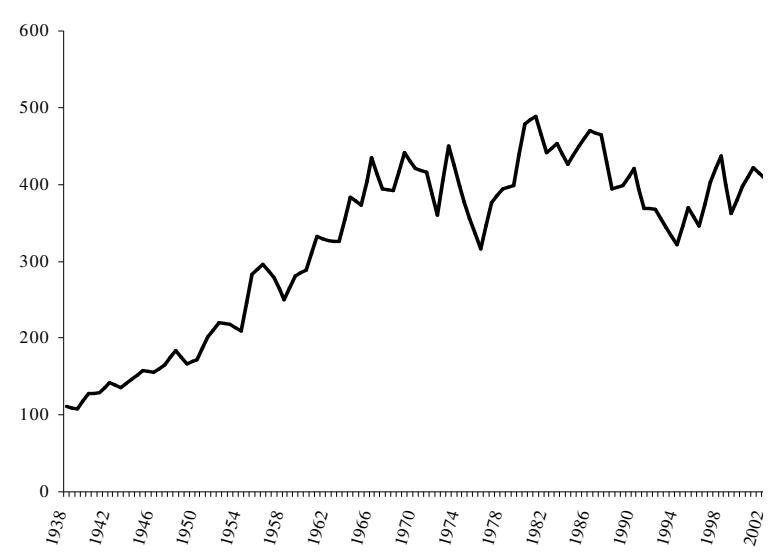

Fig. 1: Banana production data
A multivariate causal TF model for production with two inputs (income and cost): Previous results and the other aspects about the relationship between Production and Income can be found $\mathrm{in}^{[9]}$.

The existence of a one-way causal dynamic relation $x_{t}, y_{t} \rightarrow z_{t}$ and the non-presence of autocorrelation between the input series can be confirmed. Having studied the noise term structure and estimated the IRF for each input variable, the corner method and epsilon-algorithm lead finally to the model

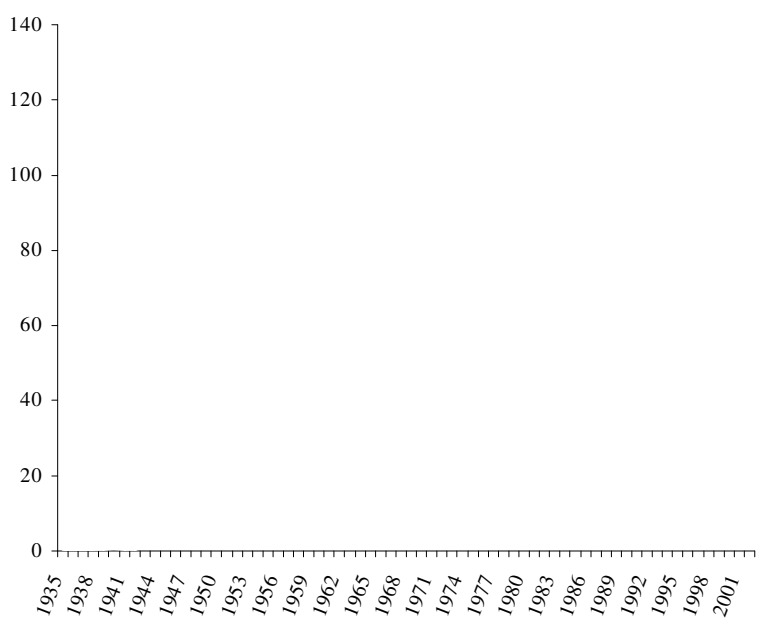

Fig. 2: Average Cost

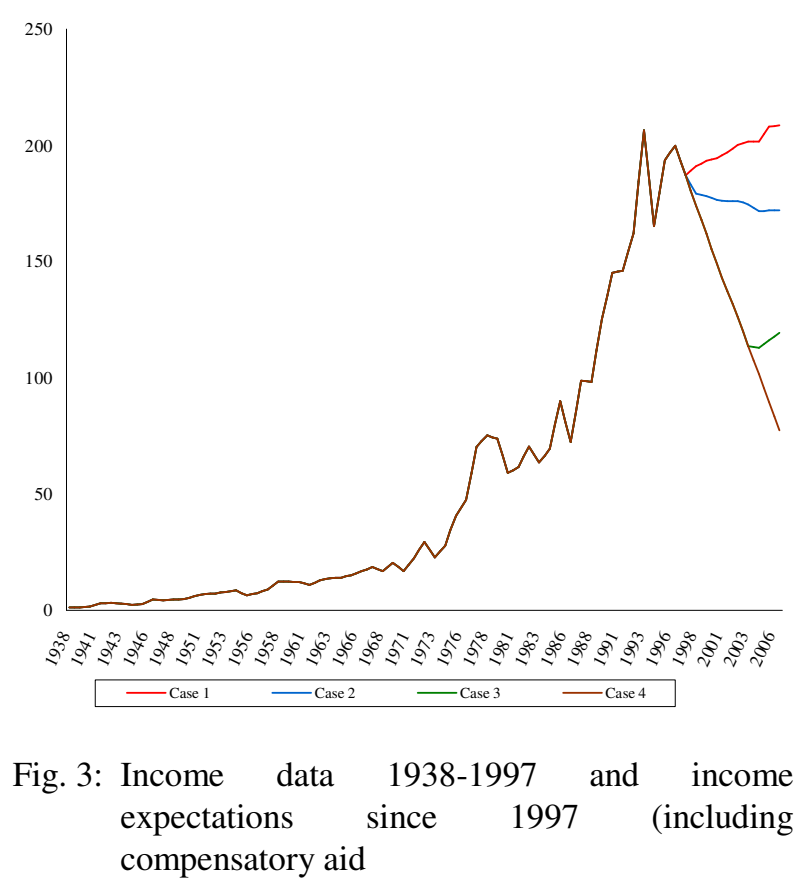




$$
\begin{gathered}
\mathrm{z}_{\mathrm{t}}=0.1091_{(2.81} \mathrm{L}^{4} \mathrm{x}_{\mathrm{t}}+0.0460_{(1.58)} \mathrm{L}^{2} \mathrm{y}_{\mathrm{t}}+ \\
\left(1+0.6798_{(-13.15)} \mathrm{L}-0.3526_{(5.74)} \mathrm{L}^{2}\right) \mathrm{a}_{\mathrm{t}}
\end{gathered}
$$

Outlier detection only produced one abnormal observation in 1955 and the re-estimated model is basically the same. Fig. 4 shows fitted models until 1993 and forecasted values considering the last observation as origin of the forecasted interval (Prediction 1) and respectively the last forecasted value as origin of the next forecasted point (Prediction 2). So, we see four lines in the Fig.: two lines for initial model and the other two for the model including the outlier effect. However, although the causal model is suitable for fitting available data it fails to provide a satisfactory response in terms of its predictive performance from 1993.

Empirical results show the farmer income is a more relevant variable for the banana farmer than Production Costs. That is why we concern with a bivariate Production-Income TF model which suggests including income expectations.

Non-causal TF model with income expectations: Next we consider the dataset for production, income and also income expectations. A main date is 1993, when the European Union (EU) introduced the compensatory aid to guarantee the banana sector subsistence, a sector actually hard conditioned by a tariff only system for the banana imports in the EU.

Specifically, four theoretical hypotheses on the income expectations are considered using 1993 as the starting date of the compensatory aid, $x_{t}^{\prime}=x_{t}^{*}, t \leq 1992$, $x_{t}^{\prime}=x_{t}^{* *}, t \geq 1993$. The four series differ in how $x_{t}^{* *}$ is generated and that includes income expectations from 1997 (Fig. 5). A sensitivity analysis is carried out considering next possible schemes.

Case 1: The banana farmer expects stable earnings throughout the next decade. According to the T-table method and epsilon-algorithm the final estimated model is

$$
\begin{gathered}
\mathrm{z}_{\mathrm{t}}=\left(0.2001_{(4.07)}+0.1296_{(2.69)} \mathrm{L}\right) \mathrm{L}^{-7} \mathrm{x}_{\mathrm{t}}+ \\
\left(1+0.8776_{(11.32)} \mathrm{L}-0.1153_{(1.48)} \mathrm{L}^{2}\right) \mathrm{a}_{\mathrm{t}}
\end{gathered}
$$

Case 2: The banana farmer expects decreasing earnings according to the European Union's decision of reducing production costs. The next specification is finally obtained

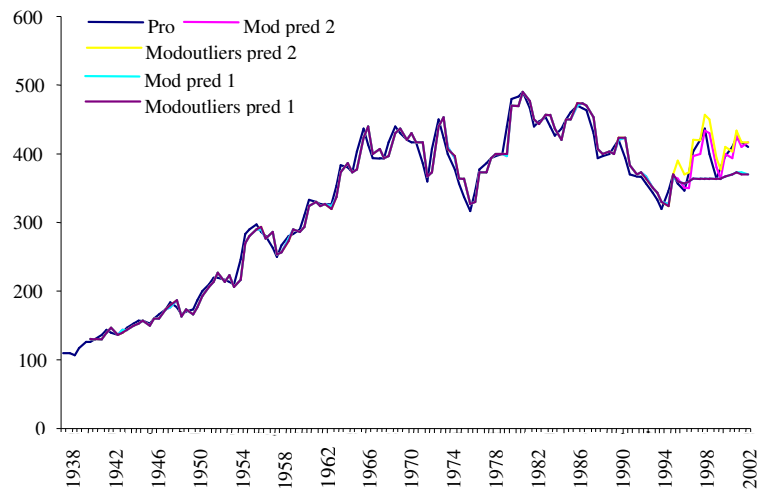

Fig. 4: TF models for banana production (income, cost)

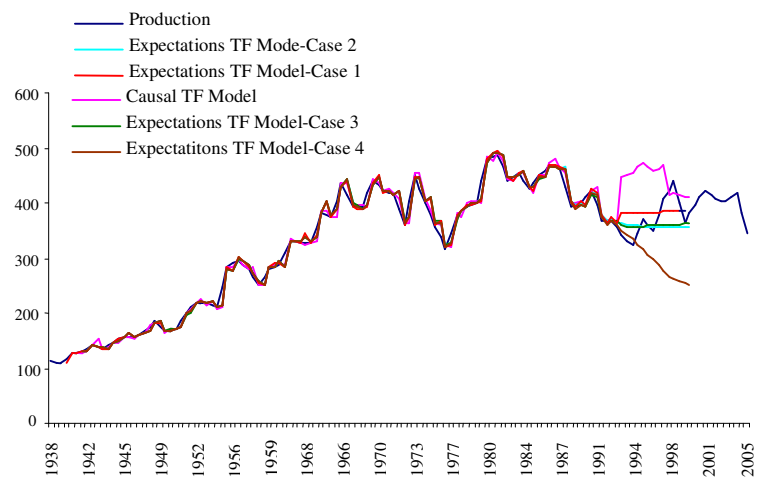

Fig. 5: Non-causal TF models for banana production

$$
\begin{aligned}
& \mathrm{z}_{\mathrm{t}}=\frac{0.1661_{(3.00)}}{1-0.5417_{(3.62)} \mathrm{L}^{2}} \mathrm{~L}^{-7} \mathrm{x}_{\mathrm{t}}+ \\
& \left(1+0.7589_{(8.81)} \mathrm{L}-0.2469_{(2.89)} \mathrm{L}^{2}\right) \mathrm{a}_{\mathrm{t}}
\end{aligned}
$$

Case 3: The banana farmer expects that after a crisis period, the earnings will return to an acceptable level. The chosen model is

$$
\begin{aligned}
& \mathrm{z}_{\mathrm{t}}=\frac{0.1645_{(3.06)}}{1-0.5543_{(3.86)} \mathrm{L}^{2}} \mathrm{~L}^{-7} \mathrm{x}_{\mathrm{t}}+ \\
& \left(1+0.7342_{(8.94)} \mathrm{L}-0.2770_{(3.41)} \mathrm{L}^{2}\right) \mathrm{a}_{\mathrm{t}}
\end{aligned}
$$

Case 4: The banana farmer does not have certainty on when crisis will finish. Against this background pessimistic the obtained model is

$$
\begin{aligned}
& \mathrm{z}_{\mathrm{t}}=\frac{0.1649_{(3.03)}}{1-0.5480_{(3.60)} \mathrm{L}^{2}} \mathrm{~L}^{-7} \mathrm{x}_{\mathrm{t}}+ \\
& \left(1+0.7959_{(10.29)} \mathrm{L}-0.2129_{(2.82)} \mathrm{L}^{2}\right) \mathrm{a}_{\mathrm{t}}
\end{aligned}
$$


Figure 5 illustrates fitting and predictive performance of the four cases and the causal TF described in 4.2.1.

We observe that all identified models provide a satisfactory response from the perspective of fitting to banana output data. However, TF models with expectations offer better predictions in the short-term. This behaviour could be explained by the fact that the farmer plans banana output not only considering his previous earnings but also taking into account other main variables, such as his future income expectation in the next three or four years. The case 3 can be considered the least realistic but it shows the optimism vision of the banana grower. The case 1 is the most desirable, although it implies reducing banana output. However, it could help to prevent the overproduction that occurred in the final years of our survey period. As it can be deduced from Case 4, without the compensatory aid, the subsistence of the sector will be threatened. An approximately half of current production would be lost and serious economic, social and ecological consequences would result.

\section{CONCLUSIONS AND OPEN QUESTIONS}

This research points up the goodness of several numerical methods closely related to the Padé Approximation for providing suitable rational structures in the context of time series modelling. Here we refer to the generalised epsilon algorithm as an alternative to the T-table method in a non-causal TF model, both proposals linked to the Padé-Laurent Approximation. Special emphasis is given to the statistical significance as a generalization of several previous results in the field of time series analysis. These related techniques can be considered "feasible alternatives" to contrast and/or confirm previously identified models.

Empirical findings emphasize the role of the epsilon table to pick up dynamic structures and also the table of asymptotic standard deviations to confirm the identified patterns and reduce possible competing models to only a few for further testing. Obtained results also stand out the goodness in terms of their asymptotic results.

For future research topics, we point out that the correct generalization of these results to VARMA models is not evident. For the corner method, for example, consideration has to be given to the rank of the matrices and not the determinants. The generalization of other numerical methods such as the r$\mathrm{s}$ and q-d algorithms to VARMA models has not yet been considered. It would also be of interest to consider the generalization of these numerical algorithms to noncausal contexts, considering the TF models with expectations.

\section{ACKNOWLEDGEMENT}

We wish to thank A. Bultheel for helpful comments on the original version of this research.

This research was supported by the National Project I+D+I n ${ }^{\circ}$ MTM2005-08571 and the Center of Mathematical Research of the Canary Islands (CIMAC).

\section{REFERENCES}

1. Baker, G.A. Jr. and P. Graves-Morris, 1996. Padé Approximants. Encyclopedia of Mathematics and its Applications, 53, Cambridge University Press. 2th Edn.

2. Beguin, J.M. et al., 1980. Identification of a Mixed Autoregressive-Moving Average Process: The Corner Method, in: O.D. Anderson, ed. Time Series, North-Holland, Amsterdam, pp: 423-436.

3. Berlinet, A. and C. Francq, 1994. Identification of a Univariate ARMA Model, Computational Statistics, 9: 117-133.

4. Boletín Mensual de Estadística Agraria. Edited by Ministerio de Agricultura, Pesca y Alimentación (MAPA). Spain.

5. Box, G.E.P. and G.M. Jenkins, 1976. Time Series analysis: Forecasting and Control, Holden Day, San Francisco, CA.

6. Brezinski, C., 1980. Padé-type Approximants and General Orthogonal Polynomials, Birkhäuser, Basel.

7. Bultheel, A., 1987. Laurent Series and their Padé Approximations, Birkhäuser, Basel/Boston.

8. Chan W.-S., 1999. A comparison of some of pattern identification methods for order determination of mixed ARMA models, Statistics and Probability Lett., 42 (1): 69-79.

9. Gil, M.C. and C. González, 2002. La Producción del Plátano en Canarias y las Expectativas del Agricultor sobre la Ayuda Compensatoria, Revista Española de Estudios Agrosociales y Pesqueros, 194: 127-146.

10. Gil, M.C. and C. González, 1997. Modelización racional de series temporales no causales: Algunas propuestas de caracterización dinámica, Estudios de Economía Aplicada, 8: 77-107. 
11. González, C. and M.C. Gil, 2003. Padé Approximation in economics, Numerical Algorithms, 33: 277-292.

12. González, C. et al., 1995. The epsilon-algorithm for the identification of a transfer-function model: Some applications, Numerical Algorithms, 9: 279395.

13. Lii, K., 1985. Transfer Function Model Order and Parameter Estimation, J. Time Series Analysis, 6 (3): 153-169.

14. Liu, L.M. and D. Hanssens, 1982. Identification of Multiple Inputs Transfer Function Models, Communi. Stat. A, 11: 297-314.

15. Liu, L.M. and G. Hudak, 1992. Forecasting Time Series Analysis Using the SCA Statistical System, Chicago, Illinois 60607-3528, USA.

16. Nuez, J.S., 2002. El Mercado Mundial de Plátanos y las empresas productoras en Canarias, 18702000, Tesis Doctoral, Universidad de La Laguna, Spain.
17. Press, W.H. and G.B. Rybicki, 1993. Large-Scale Linear Methods for Interpolation, Realisation and Reconstructing of Noisy, Irregularly Sampled Data, in A.S. Weigend and N.A. Gershrnfeld, eds. Time Series Prediction: Forecasting the Future and Understanding the Past. Addison-Wesley Publishing Company.

18. Servicio de Estadística. Consejería de Agricultura, Pesca y Alimentación del Gobierno de Canarias. http://www.gobcan.es/agricultura/otros/estadistica/ platano.htm

19. Tsay, R.S., 1985. Model Identification in Dynamic Regression (Distributed Lag) Models, J. Business and Eco. Stat., 3 (3): 228-237.

20. Wolfram, S., 2003. Mathematica, Wolfram Research, Inc. 